Revista Destaques Acadêmicos, Lajeado, v. 9, n. 3, 2017. ISSN 2176-3070 DOI: http://dx.doi.org/10.22410/issn.2176-3070.v9i3a2017.1051 www.univates.br/revistas

\title{
DENÚNCIA DE UM OLHAR FALTANTE: O AUTISMO ${ }^{1}$
}

\author{
Indianara Rovêa ${ }^{2}$, Bernardete Pretto ${ }^{3}$
}

Resumo: Este artigo propõe-se a trabalhar a questão do olhar no autismo a partir da Psicanálise, entendendo o olhar enquanto circuito pulsional e o autista enquanto um sujeito que teve uma interrupção nesse processo. Além de um percurso bibliográfico entre autores como Marie-Christine Laznik, Nilson Sibemberg, Sigmund Freud, Frances Tustin e Jacques Lacan, faz-se uma análise de uma escultura de Ron Mueck, que expressa artisticamente o que está sendo abordado neste trabalho, ou seja, a falha na constituição do olhar do autista. Nesse sentido, entende-se que o olhar que o autista nega ao mundo foi, precocemente, negado a ele enquanto circuito pulsional na relação com o Outro.

Palavras-chave: Autismo. Olhar. O Outro. Pulsão.

\section{INTRODUÇÃO}

Sabe-se que o olhar é um fator muito importante na expressão, é uma forma de comunicação, e faz parte da constituição psíquica. Isso diferencia o olhar do simples ato de ver. O entendimento dessa questão ajuda a pensar, por exemplo, sobre a abordagem da Medicina a respeito da visão, do olho enquanto órgão do corpo e dos possíveis "problemas de visão", e o que a Psicanálise aborda a respeito do olhar enquanto pulsão, movimento. Além disso, como o olhar se configura enquanto reciprocidade, troca com o outro, forma de comunicar-se? Conforme Sibemberg (1998, p.65), é através também do olhar que o Outro, aquele que exerce a função materna para o bebê humano, confere ao corpo do bebê as significações que ele atribui ao mundo, coloca-o em um circuito desejante. O nascimento do eu se dá quando o corpo do bebê é erotizado pelo olhar que a mãe, ou quem esteja exercendo sua função, lhe

1 Artigo Acadêmico produzido na disciplina de Trabalho de Conclusão de Curso II do Curso de Psicologia da Universidade do Vale do Taquari - Univates.

2 Acadêmica do Curso de Psicologia da Univates.

3 Graduada em Psicologia pela UFRGS. Mestre em Psicologia do Desenvolvimento pela UFRGS. Professora do Curso de Psicologia da Univates. 
direciona nos primeiros cuidados. Se acontece uma falha nesta apresentação de referentes ao bebê, pode ocorrer uma falta de trocas simbólicas, sendo que o mundo deste fica reduzido ao real. Assim, para iniciar, é possível pensar no autismo e nas suas consequências: isolamento, rituais, distúrbios de linguagem e a indiferença no olhar.

Para Fernandes (2000), que tentou encontrar em que momento lógico da constituição subjetiva e em quais circunstâncias dá-se o fechamento que caracteriza o quadro clínico do autista, os desdobramentos estão em torno da função do olhar do Outro primordial no processo de subjetivação. Para a autora, a partir das leituras da obra de Lacan e de Freud, o Outro primordial é o lugar onde o mundo ganha sentido, e estabelece enquanto papel desse Outro a transferência de significantes endereçados ao sujeito que está por vir. Então, e quando esse sujeito não advém? Como podemos pensar no que aí se passa?

Percebe-se, através das questões apontadas aqui, o quanto é complexo e desafiador compreender o que se passa com os sujeitos autistas. Pensa-se, ao mesmo tempo, que a partir do aporte teórico da Psicanálise, é possível entender a importância e o papel do olhar na constituição psíquica, mais especificamente no autismo, em sujeitos que, muitas vezes, ainda não se constituíram enquanto eu.

Neste artigo, pretende-se contemplar uma análise sobre a importância do olhar na constituição do sujeito, explorar o entendimento do autismo e, após, discutir a questão do olhar no autismo. Para isso, foi realizada uma pesquisa bibliográfica com base em artigos e livros de autores clássicos e contemporâneos da área da Psicanálise, que trabalham com o tema do autismo, como Marie-Christine Laznik, Frances Tustin, Nilson Sibemberg, Sigmund Freud e Jacques Lacan. Além disso, este artigo se propõe a percorrer um caminho por entre uma expressão artística, que está relacionada ao que está sendo utilizado enquanto escritos teóricos. A obra utilizada é a nomeada de "Woman with shopping" (2013), do escultor australiano e hiper-realista Ron Mueck e serve aqui como suporte para analisar a temática do olhar entre uma mãe e seu bebê. A obra despertou a atenção da pesquisadora por expressar nela um recorte momentâneo do que pode ser considerado um início para o desenvolvimento do autismo, um aspecto bastante explorado neste trabalho: $\mathrm{o}$ olhar da mãe que não é remetido ao bebê e que, por sua vez, tenta esse contato visual com sua mãe, sem receber resposta.

Entender o olhar como uma das marcas mais fortes do autismo mostrase como de extrema importância para ampliar os conhecimentos nesta área que, infelizmente, tem pouca visibilidade no decorrer da graduação em Psicologia, principalmente vista à luz da Psicanálise. Mostram-se importantes tanto o conhecimento sobre o processo de estruturação desses sujeitos quanto a possibilidade de tratamento a partir da Psicanálise, visto que a forma de atendimento aos autistas é, por muitas vezes, diminuída a apenas controlar o exterior, evitar estímulos e formatar uma rotina. 
A ciência moderna, obstinada por encontrar um saber absoluto afirmado por pesquisas genéticas, qualifica o autismo enquanto distúrbio neurológico, mesmo com uma falta de causas orgânicas comprovadas. Em meio a isso, por vezes ignora-se o sujeito que ali está, desconsideram-se as responsabilidades e influências tanto do bebê quanto dos envolvidos nesse processo, enquanto sujeitos de desejos e responsáveis pela inscrição subjetiva das suas crianças. Será assim tão simples? A rotulação do autismo enquanto distúrbio neurológico pode promover um avanço nas discussões? De que outras formas podemos encarar e considerar o autismo? Há outros meios de olhar para essas crianças e proporcionar um vir a ser, já que o autismo pode ser visto como uma falta da inscrição simbólica necessária para o nascimento de um sujeito?

Compreende-se que um diagnóstico de autismo na infância é bastante complexo e que não deveria explicar e abafar a atenção a essas crianças, reduzindo-as às características descritas nos manuais. Mas entender mais sobre a doença é uma forma de, considerando cada sujeito que temos à frente, saber minimamente o que pode ter ocorrido, sem esquecer que cada sujeito é singular e assim deve ser olhado e atendido.

O olhar é um meio de linguagem e comunicação com o mundo, e o fato de uma criança autista apresentar, muitas vezes, um olhar vazio, que não se fixa e não é recíproco, e por isso parecer não se relacionar com o que olha, é a questão instigante que impulsionou a elaboração deste trabalho. Com isso, tentando compreender melhor esse estado autista, pretende-se contribuir com futuras pesquisas e auxiliar acadêmicos que se interessarem pelo tema, além de fazer pensar nas práticas e percepções que se tem atualmente sobre o assunto.

\section{A FALTA DO LAÇO COM O OUTRO: O AUTISMO PARA A PSICANÁLISE}

O autismo é um quadro que envolve muitas discussões e concepções, tanto se tratando de diagnóstico e sintomas quanto das causas que o gerariam. Na visão da Psicanálise, é importante conhecer sobre a doença, mas é muito mais importante considerar que cada sujeito é singular e vive de uma forma particular seus sintomas. O desenvolvimento do autismo não se dá pela existência de fatores determinantes que seriam sempre os mesmos e vividos igualmente entre todos os autistas. Meira (1998) escreve sobre o quanto pode ser negativo receber a classificação de autismo sem ter um trabalho com os envolvidos:

[...] isto marca uma diferença significativa no discurso dos pais, que produz, na criança, uma marca que a instala em uma rede onde o real toma corpo e a possibilidade de aceder a uma inscrição se fratura. Ela passa a ter como referência [...] um nome que não a refere à linhagem familiar, mas sim a classificações médicas às quais os pais 
se referem quando são chamados a falar sobre seu filho (MEIRA, 1998, p. 73).

Por isso, para Meira (1998), a importância de entender que uma criança não é autista, mas está inserida no autismo, e que a partir de algumas ações, tais como: inscrever um nome onde há um diagnóstico, apresentar a cultura e incluir na rede simbólica da família, pode-se atribuir a essas crianças outro caminho que não a simples execução do comportamento que lhes foi imposto.

Atualmente, o DSM-5 (Manual Diagnóstico e Estatístico de Transtornos Mentais, 2014) tem sido utilizado para diagnóstico de autismo. Nele, o autismo aparece no item denominado Transtorno do Espectro Autista e encontra-se a seguinte definição:

[...] prejuízo persistente na comunicação social recíproca e na interação social e padrões restritos e repetitivos de comportamento, interesses ou atividades. Esses sintomas estão presentes desde o início da infância e limitam ou prejudicam o funcionamento diário (DSM-5, 2014, p. 53).

Percebe-se, nesta breve definição, a ênfase nos sintomas e nos prejuízos que envolvem o autismo. Pode-se pensar que, mesmo que eles estejam presentes neste transtorno, se tomados como determinantes únicos, acabam impedindonos de observar a singularidade do sujeito autista e, principalmente, de tratá-lo como além dessa definição posta.

Além de toda essa problematização acerca dos diagnósticos, é importante conhecer sobre a síndrome autística e o que muitas vezes leva a comportamentos que são vistos como, primordialmente, a falta de contato com os outros. A primeira descrição das características do autismo aconteceu em 1943, quando Léo Kanner, um psiquiatra austríaco, relatou a sua observação de um grupo de onze crianças, e os comportamentos foram denominados por ele como Distúrbios Autísticos do Contato Afetivo. Nas palavras de Sibemberg (1998):

O comportamento delas era marcado por um isolamento extremo, com atitude de indiferença frente a frente com as pessoas e os objetos; havia necessidade de imutabilidade, com permanência e estabilidade das referências, com frequentes verificações ritualizadas; estereotipias gestuais, como revolver os dedos em frente à face, caminhar na ponta dos pés, rodopiar em torno de si mesmo, balanceio rítmico do corpo para frente e para trás estavam presentes; os distúrbios de linguagem variavam desde a ausência completa de linguagem, passando por repetições de jargões sem significação, ecolalia, incapacidade de manejar pronomes pessoais e construção de neologismos (SIBEMBERG, 1998, p. 60). 
Desde essa descrição, muitas discussões foram feitas, e continuam os debates sobre as causas e as possibilidades de tratamento do autismo. Inclusive sobre as definições, é possível encontrar diferentes abordagens e entendimentos a respeito do que envolve a síndrome autística. O termo autístico foi utilizado por Freud (1969) para referir-se ao bebê que se volta para si mesmo, tomando o próprio corpo como objeto de prazer, e rejeita o exterior por um período. Aqui, Freud ainda se referia a um momento do desenvolvimento que pode ser considerado esperado, pelo qual todos passam.

A autora Tustin (1975) considera que o

[...] autismo significa viver em termos do próprio eu (self), o que está de acordo com o fato, por demais constatado, de que uma criança em estado de autismo parece centrada em si mesma, já que pouco reage ou responde ao mundo que a rodeia. Mas, paradoxalmente, uma criança nesse estado não se dá conta, em verdade, do que ser um eu (self) significa (TUSTIN, 1975, p. 9).

Laznik (2013) defende que o autismo pode ser considerado uma resposta clínica da falta de instauração de algumas estruturas psíquicas que acarretam em déficits, como o cognitivo. A deficiência cognitiva viria, então, de uma não construção das estruturas psíquicas, e não o contrário, como muitos discursos atualmente têm defendido. A autora complementa que

[...] é deste registro propriamente psíquico que vou tratar, pois é o único no qual podemos intervir. É aí que podemos falar de uma prevenção possível da organização da síndrome autística. Intervir para que se instaurem as estruturas mesmas que suportam o funcionamento dos processos de pensamento inconsciente. Intervir antes da organização dos déficits cognitivos, pois há verdadeiramente uma psicossomática do autismo: a não-instauração das estruturas psíquicas lesa rapidamente o órgão que as suporta (LAZNIK, 2013, p. 21-22).

Laznik (2013) também nos apresenta dois sinais que podem ser notados bem precocemente na vida do bebê e que levantam a hipótese de autismo. $\mathrm{O}$ primeiro deles é o fato de não ocorrer a troca de olhar entre a mãe e o bebê, que pode ser um indicativo de que o estádio do espelho não ocorreu, ou ocorreu mal; o estádio do espelho será abordado no próximo capítulo. O segundo sinal seria a não constituição do circuito pulsional completo. A autora diz que o circuito pulsional é formado por três fases: a primeira delas é quando o bebê se conduz para o objeto oral e o segura; a segunda fase é quando o bebê tem como objeto da pulsão parte do seu próprio corpo; e, por fim, o terceiro tempo ocorre quando o bebê se coloca como objeto do outro, assujeita-se a esse outro, a essa mãe, e é com essa terceira fase que surge o sujeito da pulsão. Para a autora, a terceira fase não ocorre, pois é essa fase que irá dar surgimento a um 
novo sujeito, que irá estruturar simbolicamente o aparelho psíquico, e essa estruturação não acontece nos autistas, pois não ascendem ao campo do Outro. Essa não-estruturação do aparelho psíquico faz com que a criança se volte para si mesma e não possa estabelecer laços com outros.

Pensando, então, que o olhar é uma forma de ligação, de relação, buscase compreender sua relevância na constituição psíquica.

\section{O OLHAR NA CONSTITUIÇÃO PSÍQUICA}

Faz parte da vida humana a relação com outras pessoas, que se realiza de diversas formas, utilizando-se de diferentes meios. Sabe-se que o ser humano, nos primeiros períodos de sua vida, é completamente dependente de um Outro que o alimente, o proteja, o acarinhe, olhe para ele. Se essa condição de dependência tem a ver, primeiramente, com a prematuridade do bebê a nível biológico, orgânico, também se configura como uma dependência deste enquanto corpo ainda não habitado pela subjetividade. Esta, também se constitui a partir da troca com o Outro, segundo nos ensina a Psicanálise.

As trocas entre uma mãe (ou aquele que exerça esta função junto à criança) permitem que a criança ingresse no mundo da linguagem. Linguagem aqui entendida como um possível elo de ligação entre a criança e o mundo que a cerca, constituído tanto por pessoas como por imagens, sons, cheiros... Para Manenti (1988):

O corpo do bebê deixa de ser real, um pedaço de carne, para ser imaginário e simbólico na medida em que seja erotizado pelo olhar, a voz, o cheiro e o toque diferenciado que a mãe lhe endereça nos cuidados primários e que seja recoberto por significantes que lhe constituam referências simbólicas. É o nascimento do eu (MANENTI, 1998, p. 123).

O nascimento do sujeito psíquico, portanto, vai se dando através das marcas no corpo, marcas entendidas aqui como inscrições simbólicas, propiciadas por aquele que exerce a função materna. Segundo Sibemberg (1998):

A percepção no humano se organiza através das significações que são conferidas às fronteiras do corpo e ao agrupamento dos objetos. Assim, através da linguagem, na relação com o outro, a criança vai construindo seus referentes imaginários e simbólicos, regulando um funcionamento corporal que transforma um corpo puramente orgânico em corpo erógeno (SIBEMBERG, 1998, p. 65).

Para Manenti (1998, p. 124), o olhar é um ato de linguagem, é um ato simbólico. Portanto, para a autora, se diferencia do ato de ver, do ato da visão. Ainda no campo do ver, existem diferentes perspectivas: para o oftalmologista, 
vemos coisas a partir dos olhos do corpo, mas para a Psicanálise, vemos imagens a partir do eu. Não vemos a coisa em si, não enxergamos um mundo de coisas, mas vemos o mundo através de imagens, e quando vemos uma imagem, essa visão consiste na percepção daquilo, própria de cada pessoa.

O olhar materno remetido para a criança marca nela uma existência, e quando esta se reconhece, devolve o olhar para o mundo. Segundo Sibemberg (1998, p.65), "se, por alguma razão, há uma falha precoce na apresentação dos referentes imaginários e simbólicos ao bebê, a criança pode ficar excluída do campo das trocas simbólicas da linguagem, reduzida ao real de um corpo perceptivo não subjetivado".

Lacan (1949), no escrito "O Estádio do Espelho como formador da função do [eu] tal como nos é revelada na experiência analítica", destaca a importância do momento em que a criança reconhece sua imagem no espelho, aludindo aí não somente ao espelho plano, físico, mas ao olhar da mãe enquanto espelho para a criança. "Basta compreender o estádio do espelho como uma identificação, no sentido pleno que a análise atribui a esse termo, ou seja, é a transformação produzida no sujeito quando ele assume uma imagem" (LACAN, 1998, p. 97). Dolto e Nasio (2008, p. 47) nos dizem que "não existe apenas o espelho plano, há sobretudo o espelho que o outro é para nós". Segundo Roudinesco e Plon (1998, p. 194), o estádio do espelho ocorre entre o sexto e o décimo oitavo mês de vida e expressa o momento em que "a criança antecipa o domínio sobre sua unidade corporal através de uma identificação com a imagem do semelhante e da percepção de sua imagem num espelho". Tais definições nos mostram o quanto a experiência de olhar-se e olhar para o outro no espelho tem uma grande importância no reconhecimento de um corpo, do próprio corpo. É necessário também para a constituição psíquica, que ocorre quando o Outro, aquele que exerce a função materna, nos apresenta o que é nosso e o que é do mundo, nos mostra quem e como somos, faz com que sejamos separados em uma unidade corporal e diferenciados dos outros. Constituimo-nos, então, através do que é depositado, em nós, pelo Outro.

Pode-se pensar nessa temática do olhar também através de diferentes manifestações artísticas. Uma delas, escolhida neste trabalho para ampliar a possibilidade de compreensão sobre a importância do olhar, é a escultura. Como peça chave para essa discussão, utiliza-se o escultor Ron Mueck, que demonstra a realidade através de obras chocantes e impactantes, que levantam questões e reflexões acerca da vida cotidiana. Ron Mueck é um escultor hiperrealista que utiliza efeitos especiais cinematográficos para criar suas esculturas, reproduz traços reais com perfeição, mas brinca com as escalas para expressar sensações. Nasceu em Melbourne, na Austrália, em 1958. Extremamente detalhista, usa materiais como resina, fibra de vidro, silicone e argila. Tudo é feito manualmente, os cabelos e pelos são colocados um a um, as peças são moldadas em argila, depois fundidas em silicone a partir de um molde (CRUZ, 2015). 
Em uma escultura de Ron Mueck, de 2013, chamada de "Woman with shopping", percebe-se através da expressão artística uma manifestação do olhar congelado e cansado de uma mãe, que apenas carrega um bebê, sem contato e sem afeto, como se ele se assemelhasse às compras que estava carregando.

Figura 1 - Escultura "Woman with shopping" (2013) de Ron Mueck

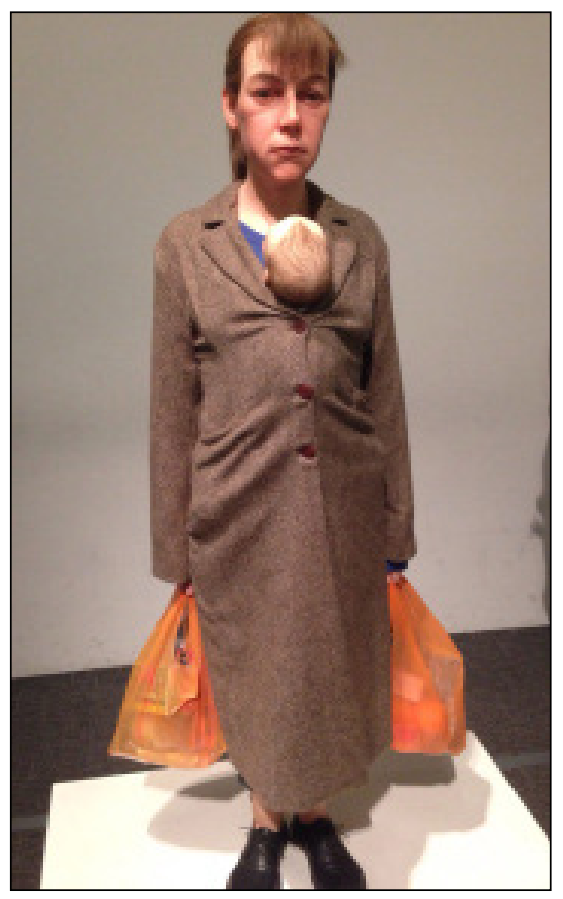

Fonte: www.clinpsiabc.wordpress.com/2015/02/24/a-inconsistencia-do-olhar/

Apesar de tratar-se de um recorte de um momento estático, a falta de contato da mãe com o bebê e a maneira como esse bebê é carregado manifesta a relação que existe estabelecida ali, em que carregar uma vida é o mesmo que carregar as sacolas de compras. Se todos os momentos dessa mãe com esse bebê forem frios como nessa expressão, de onde o bebê receberá a significação de que necessita para que se desenvolva a estrutura psíquica? Sucessivos fracassos farão a criança retirar-se e não mais voltar seu olhar para o mundo. Percebese o rosto carregado de apatia e de indiferença da mãe, "prendendo" o bebê por pressão no casaco, que por sua vez lança o rosto e o olhar para a mãe, sem receber nada em troca, sem ser respondido, em um apelo por um olhar que poderia ser a significação de que precisava para que se constituísse enquanto sujeito. 
Figura 2 - O rosto do bebê na Escultura "Woman with shopping" (2013)

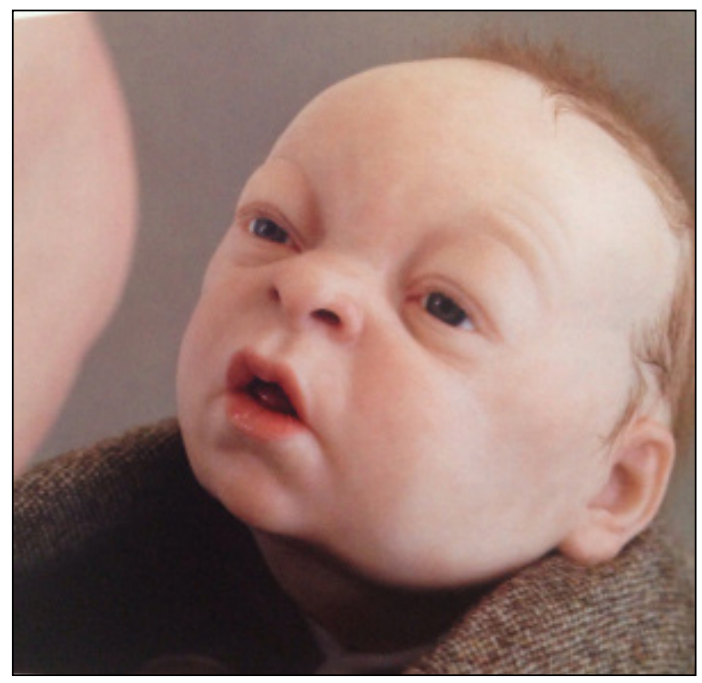

Fonte: www.clinpsiabc.wordpress.com/2015/02/24/a-inconsistencia-do-olhar /

Assim, é esperado que a constituição humana passe pelo receber e devolver o olhar, também como forma de expressão e comunicação com o outro. E o que ocorre quando o olhar se congela? Nada chama a atenção? Não é carregado de sentido? Não quer ou não consegue relacionar-se, fixar-se? Pode mesmo ser um olhar vazio ou está querendo expressar algo, mesmo que seja a expressão de uma falta?

Haveria, portanto, uma falha da operação significante, uma falha materna no processo de antecipação de um sujeito, o que impediria o estabelecimento da relação especular, que é o contato através da troca de olhares, e do circuito pulsional completo. Para entendermos sobre o circuito pulsional, precisamos, inicialmente, saber sobre a pulsão. No Vocabulário da Psicanálise de Laplanche e Pontalis (1983), pulsão é um "processo dinâmico que consiste numa pressão ou força (carga energética, fator de motricidade) que faz o organismo tender para um objetivo" (LAPLANCHE; PONTALIS, 1983, p. 506). Freud (1915/1996) conceitua a pulsão

como um conceito situado na fronteira entre o mental e o somático, como o representante psíquico dos estímulos que se originam dentro do organismo e alcançam a mente, como uma medida da exigência feita à mente no sentido de trabalhar em consequência de sua ligação com o corpo (FREUD, 1915/1996, p. 127).

Ressalta também que se difere de algo simplesmente orgânico e da ordem da necessidade, por tratar-se de uma força constante que vai além dos estímulos puramente fisiológicos. Essa força constante pode ser percebida 
no olhar quando tratamos de pulsão escópica. Lacan, em seu Seminário XI (1964/1998), nos diz que a pulsão escópica é o prazer de olhar e de se fazer ser olhado, ou seja, o objeto da pulsão escópica é o olhar. Vai destacar também o dito de Freud quando descreve que a partir do processo circular da pulsão escópica, o círculo enquanto olhar do bebê direcionado para o Outro e o Outro retornando ao bebê esse olhar, dá-se o surgimento de um novo sujeito, aquele que se mostra para ser olhado, o sujeito da pulsão.

Considerando o que foi abordado no primeiro capítulo sobre o autismo e no segundo capítulo sobre o olhar na constituição psíquica, será apresentado uma relação entre as duas questões buscando-se compreender o olhar do autista: que não se fixa e é, então, nômade.

\section{O OLHAR NÔMADE DO AUTISTA}

"Seus olhos estavam sempre baixos, e seu olhar, muito oblíquo, quase nunca encontrava alguém" (LAZNIK, 1997, p. 14). Essa é a descrição do olhar de uma criança atendida por Laznik (1997). Entende-se que a ausência da fixação do olhar do autista atesta a não-constituição do laço com os outros, por falta, primeiramente, de uma estruturação psíquica que comporte o eu. O voltar-se para si, no autismo, é demonstrado no corpo pelos olhos que, simbolicamente, estão olhando para dentro, e não para o mundo.

Isso nos leva a colocar que a impossibilidade da instauração conveniente do estádio do espelho na criança poderia ser efeito de uma falha ao nível do reconhecimento primeiro. Isso daria conta do evitamento [...] de tudo o que poderia ter ligação com o olhar da mãe, no sentido da presença, de investimento libidinal (LAZNIK, 2013, p. 46).

Existem percepções de que no autista há uma "fuga" no olhar, ou uma dificuldade em fixar o olhar, e isto não está ligado a uma dificuldade de visão orgânica. Temos, então, um olhar nômade: sem lugar fixo, sempre se movimentando em busca de algo, sem ligação com algo ou alguém. Nenhuma troca é possível, nenhuma forma de comunicação chama a atenção a ponto de pairar sobre. O olhar está, apesar de parecer lançado para fora, voltado para dentro: afinal, já foi negado anteriormente.

A falta da fixação do olhar em algo que chame a atenção é um dos elementos que permite considerar a chance de não haver ainda uma constituição psíquica estabelecida, em que o sujeito não se reconhece e não pode, então, reconhecer o Outro: "Este não-olhar entre a mãe e a criança, assim como o fato da mãe não se dar conta disso, constitui um dos sinais primordiais que permitem pensar na hipótese de um autismo nos primeiros meses de vida" (LAZNIK, 2013, p. 38). 
Lacan (1997), no seminário sobre a angústia dizia que: “... a primeira emergência (de uma comunicação por parte daquele que ainda é um sujeito [S] não barrado) é apenas um 'quem sou eu?' inconsciente, já que é informulável, ao qual responde, antes que se formule, um 'tu és', ou seja, ele recebe sua mensagem primeiramente sob forma invertida." Acrescentarei, ele recebe sua mensagem do Outro sob forma invertida (SIBEMBERG, 1998, p. 68).

Jerusalinky (1993) nos diz que no autismo ocorre uma ausência de inscrição que coloca a criança sempre em uma posição de exclusão no que se refere à demanda do Outro. Seria por isso, por estar excluído da demanda do Outro, que nega o olhar enquanto contato, já que está colocado em um lugar de exclusão.

É por isso que o autista recebe qualquer manifestação do laço social, seja do modo direto ou indireto, como uma demanda de ausentificação. É por isso que a criança autista vira as costas àquele que a ela se dirige, ou se opõe especificamente a incorporar os objetos que lhe são oferecidos pelo outro. [...] há uma posição em relação ao significante que é aquela que lhe diz respeito, ou seja, a da exclusão (JERUSALINSKY, 1993, p. 64).

Pensa-se que o primeiro momento que afirma a exclusão do autista é na sua relação precoce com o Outro, quando dirige o olhar e não recebe o olhar de volta, ele é excluído do circuito pulsional, há uma interrupção, um corte que define a repetição de ausentificação que se dará no autismo. 
Figura 3 - A mãe e o bebê na Escultura de Ron Mueck

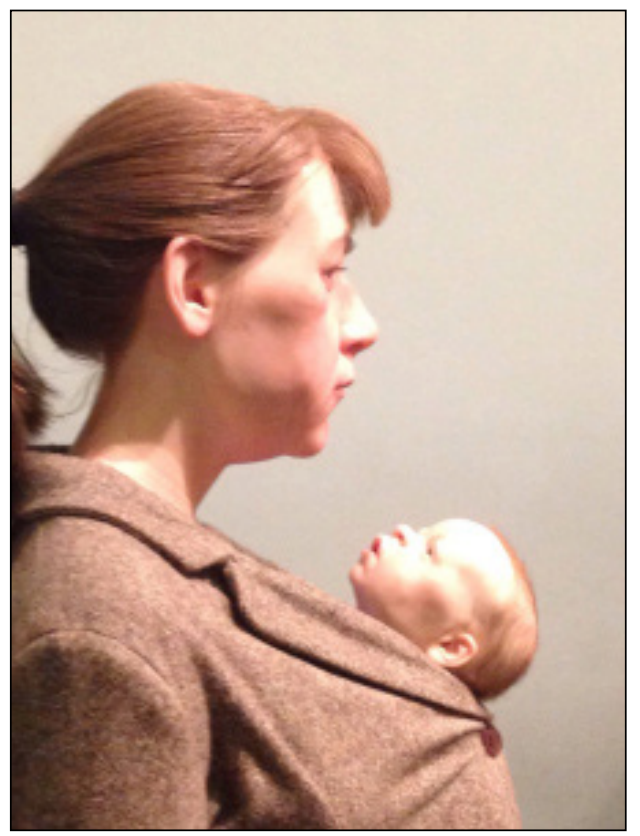

Fonte: www.clinpsiabc.wordpress.com/2015/02/24/a-inconsistencia-do-olhar/

Laznik (2013) alerta que a imagem originária do corpo só pode se formar no olhar do Outro, e quando o bebê se dirige para quem o segura é para encontrar nesse olhar a confirmação da sua imagem. Algumas mães não se deixam levar por nenhuma imagem antecipadora, veem apenas o próprio real, e a falta de antecipação torna impossível o advir posterior. Pode-se pensar nesse sentido a partir da Figura 3 - A mãe e o bebê na Escultura de Ron Mueck, quando percebemos o olhar do bebê dirigido para a mãe em uma tentativa de encontrar no olhar dela uma confirmação de que é um alguém, um retorno. Nessa etapa da vida, o bebê ainda não se distingue da mãe e do que o rodeia, "no desenvolvimento emocional individual, o precursor do espelho é o rosto da mãe" (WINNICOTT, 1975, p. 153), portanto ao olhar para a mãe o bebê vê a si mesmo e constrói, assim, a imagem de si. Porém, quando o olhar da mãe nega essa tentativa, frusta o bebê e faz com que a percepção de Eu não nasça naquela criança, interrompendo, assim, o circuito pulsional, que não se fecha enquanto círculo, vai na direção da mãe e não volta em direção ao bebê.

Assim, o olhar que não é recebido pelo Outro, necessário para a constituição psíquica, faz com que o autista se volte para si mesmo, voltando até mesmo o olhar para dentro. Podemos compreender o olhar nômade do autista como uma falha na constituição deste olhar enquanto pulsão, uma falha no circuito pulsional que faz com que não nasça um sujeito desejante de olhar e ser olhado. 


\section{CONSIDERAÇÕES FINAIS}

"Atrás do que diz um discurso, há o que ele quer dizer e, atrás do que quer dizer, há ainda um outro querer-dizer, e nada será nunca esgotado."

Jacques Lacan

Pensa-se que é por ser possível ter uma percepção mais ampliada sobre o tema do Autismo, a partir do aporte teórico da Psicanálise, tendo em vista que o assunto é pouco trabalhado no decorrer do curso de Psicologia. Este trabalho tornou possível responder algumas interrogações que se colocaram no início deste percurso, mas além disso, foi capaz de abrir novas perguntas sobre o tema e suscitar um desejo ainda maior de entendimento tanto do processo de constituição quanto de formas de tratamento que se pode oferecer aos sujeitos autistas. Com a análise da escultura "Woman with shopping" (2013) de Ron Mueck foi possível também considerar uma manifestação artística que se relaciona com o tema abordado e ir além da pesquisa teórica psicanalítica, podendo relacionar e fazer conversar dois mundos distintos que abordam de maneiras diferentes a vida humana e seus movimentos.

A partir do capítulo A falta do laço com o outro: o autismo para a Psicanálise, pode-se entender o percurso conceitual que o autismo foi sofrendo com o passar do tempo e com o avançar das discussões e estudos sobre o assunto. No capítulo $\mathbf{O}$ olhar na constituição psíquica, a abordagem se dá no sentido de compreender a importância que o olhar tem enquanto estruturação psíquica, e o quanto esse processo de olhar e ser olhado, visto aqui como um circuito pulsional, vai ser significativo na vida humana para constituir um sujeito da pulsão. No terceiro capítulo, nomeado de $\mathbf{O}$ olhar nômade do autista, constituiu-se a relação entre o olhar do autista que não se remete aos sujeitos e uma falta na troca com o Outro, entendendo que o autista olha para dentro por ter sido frustrado na sua tentativa de ser olhado, ou seja, o olhar que o autista não remete ao mundo foi, primeiramente, negado a ele na sua relação com o Outro. $\mathrm{O}$ autista não reconhece a si mesmo enquanto um sujeito psíquico e não pode, então, reconhecer os outros ao seu redor.

Entender o que se passa no quadro de autismo pode colaborar com o atendimento prestado a esses sujeitos e também pode contribuir com futuras pesquisas que possivelmente serão feitas acerca do tema, já que o presente artigo visa fazer parte de uma discussão e não fechar ou concluir as percepções que se tem do autismo e de uma de suas marcas mais fortes: o olhar.

\section{REFERÊNCIAS}

AMERICAN PSYCHIATRIC ASSOCIATION. DSM-5: manual diagnóstico e estatístico de transtornos mentais. 5. ed. Porto Alegre: Artmed, 2014. 
CRUZ, Luiz. O Escultor Ron Mueck, 2015. Disponível em: <http:/ /virusdaarte.net/oescultor-ron-mueck/>.

DOLTO, Françoise; NASIO, Juan David. A criança no espelho. Rio de Janeiro: Jorge Zahar, 2008.

FERNANDES, Lia. O olhar do engano: Autismo e o Outro Primordial. São Paulo: Escuta, 2000.

FREUD, Sigmund. Formulações sobre dois princípios do funcionamento psíquico, v. XII. Rio de Janeiro: Imago, 1969.

FREUD, Sigmund. As pulsões e suas vicissitudes (1915). In: FREUD, Sigmund. Obras psicológicas completas de Sigmund Freud: Edição Standard Brasileira. Rio de Janeiro: Imago, 1996, v. XIV, p. 115-144.

JERUSALINKY, Alfredo. Psicose e autismo na infância: uma questão de linguagem. Psicose. Boletim da Associação Psicanalítica de Porto Alegre. Ano 4, n 9, 1993.

LACAN, Jacques. O estádio do espelho como formador da função do eu. In: Lacan, Jacques. Escritos. Rio de Janeiro: Zahar, 1998.

LACAN, Jacques (1964). O Seminário, livro XI: os quatro conceitos fundamentais da Psicanálise. Rio de Janeiro: Jorge Zahar Ed., 1998.

LAPLANCHE, Jean; PONTALIS, Jean-Bertrand. Vocabulário da Psicanálise. $7^{\text {a }}$ ed. São Paulo: Martins Fontes, 1983.

LAZNIK, Marie-Christine. A voz da sereia: O autismo e os impasses na constituição do sujeito. Salvador: Ágalma, 2013.

LAZNIK, Marie-Christine. Rumo à palavra: Três Crianças Autistas em Psicanálise. São Paulo: Escuta, 1997.

MANENTI, Patrícia Balestrin. O olhar do cego. In: Publicação do Centro Lydia Coriat. Escritos da Criança. $n^{\circ}$ 5. Porto Alegre, 1998. p. 122-126.

MEIRA, Ana Marta Goelzer. Algumas considerações a respeito do diagnóstico de autismo na infância. In: Publicação do Centro Lydia Coriat. Escritos da Criança. $n^{\circ} 5$. Porto Alegre, 1998. p. 73-78.

ROUDINESCO, Elisabeth; PLON, Michel. Dicionário de Psicanálise. Rio de Janeiro: Jorge Zahar, 1998.

SIBEMBERG, Nilson. Autismo e Linguagem. In: Publicação do Centro Lydia Coriat. Escritos da Criança. $n^{\circ}$ 5. Porto Alegre, 1998. p. 60-71.

TUSTIN, Frances. Autismo e psicose infantil. Rio de Janeiro: Imago, 1975.

WINNICOTT, Donald. O brincar e a realidade. Rio de Janeiro: Imago, 1975. 